\title{
Desempenho de seis híbridos de repolho na época chuvosa de Areia-PB.
}

\author{
Ademar P. de Oliveira; Janete S. Costa; Caciana C. Costa \\ UFPB- Centro de Ciências Agrárias, 58.397-000 Areia-PB. Email: ademar@cca.ufpb.br
}

\section{RESUMO}

O objetivo do trabalho foi avaliar o comportamento dos seis híbridos de repolho Midore, Rotan, Saikô, Fuyu, Matsukaze e Roxo em condições chuvosas. O ensaio foi conduzido no Centro de Ciências Agrárias da Universidade Federal da Paraíba, em Areia-PB, no período de abril a julho de 1996 em Latossolo Vermelho-Amarelo. O delineamento experimental utilizado foi o de blocos casualizados, testando-se seis híbridos em quatro repetições, em parcelas com 20 plantas úteis, espaçadas de 0,80 m entre fileiras e 0,40 m entre plantas. Avaliaram-se as características: produtividade, peso médio, índice de formato e compacidade de cabeça, além de tolerância à podridão-negra. Os resultados obtidos indicaram o híbrido Midore, como opção de cultivo para a época chuvosa em Areia, considerando-se o peso médio de $1,314 \mathrm{~kg}$, produtividade de 30,62 t/ha, formato arredondado da cabeça, compacidade e alta tolerância à podridão-negra, quando comparado com a performance do Matsukaze, considerado padrão comercial em Areia.

Palavras-chaves: Brassica oleracea var. capitata L., Xanthomonas campestris pv. campestris, produção, compacidade, tolerância à podridão-negra.

\begin{abstract}
Performance of six cabbage hybrids during the rainy season of Areia-PB.

The objective of the work was to evaluate the behaviour of six cabbage hybrids: Midore, Rotan, Saikô, Fuyu, Matsukaze and Roxo in rainy conditions. The study was conducted in the Center of Agrarian Sciences of the Federal University of Paraíba, in AreiaPB, on a Red-yellow Latossoil, between the period of April to July 1996. The experiment was laid out in a randomised block design, with six treatments and four repetitions, in plots of 20 analyseable plants, spaced $0.80 \mathrm{~m}$ between rows and $0.40 \mathrm{~m}$ between plants. Productivity, medium head weight, format index, head compactness, and tolerance to black rot were evaluated. The results obtained indicated the hybrid Midore as an option for cultivation in the rainy season in Areia, when considering a productivity of $30.62 \mathrm{t} / \mathrm{ha}$, medium weight of $1.314 \mathrm{~kg}$, compact and rounded head format, and high tolerance to black rot, compared to the performance of Matsukaze, considered commercial pattern in Areia -PB.
\end{abstract}

Keywords: Brassica oleracea var. capitata L., Xanthomonas campestris pv. campestris, production, compactness, tolerance to black rot.

\section{(Aceito para publicação em 22 de março de 1999)}

$\mathrm{D}_{\mathrm{p}}^{\mathrm{e}}$ entre as variedades botânicas da espécie Brassica oleracea L., cultivadas no Brasil, o repolho é a primeira em importância econômica (Filgueira, 1982). É uma hortaliça de fácil cultivo, baixo custo de produção, alta produtividade, versatilidade à mesa e indústria e excelente composição nutritiva (Sonnenberg, 1985). Face à sua alta capacidadede de adaptação às distintas situações do meio ambiente, à sua elevada taxa de crescimento e geração de alimentos com atenuado conteúdo de vitaminas e sais minerais essenciais à dieta humana, constitui-se numa das hortaliças mais saudáveis na dieta humana (Silva Júnior et al., 1987).

A partir da década de 60 , em função do melhoramento genético realizado por pesquisadores brasileiros e da introdução de híbridos tolerantes ao calor, o cultivo do repolho no Brasil tem sido feito com híbridos introduzidos do Japão, em substituição à antiga cultivar Louco. Já existem no mercado brasileiro alguns híbridos e cultivares de repo- lho de boa aceitação comercial (Castellane \& Braz, 1991). No entanto, muitos são suscetíveis à podridão-negra das crucíferas (Xanthomonas campestris pv. campestris) e não têm formato desejável ou boa compacidade da cabeça, dentre outras características (Giordano et al., 1985).

O repolho está convertendo-se em uma das principais hortaliças cultivadas na região de Areia-PB. O híbrido Matsukaze tem apresentado, entre os produtores da região, excelente aceitação e tolerância à podridão-negra, uma das principais doenças da cultura do repolho (Giordano et al., 1985). Nesta região, ocorre um período chuvoso que abrange os meses de março a agosto com temperatura média de $23^{\circ} \mathrm{C}$, umidade relativa média acima de $80 \%$ e um período de estiagem nos meses de setembro a fevereiro, quando verificam-se elevada temperatura média e alta umidade relativa do ar. Predomina o Latossolo Vermelho-Amarelo. As técnicas de cultivo utilizadas são as mesmas de outras regiões do Brasil cultivando-se principalmente o híbrido Matsukaze. Na época chuvosa há grande incidência da podridão-negra das crucíferas, tornandose um problema sério para o cultivo desta hortaliça na região. Este trabalho teve como objetivo avaliar o comportamento de híbridos de repolho, na época chuvosa na região de Areia-PB.

\section{MATERIAL E MÉTODOS}

O ensaio foi conduzido na área experimental do Centro de Ciências Agrárias da Universidade Federal da Paraíba, em Areia - PB, em solo Latossolo Vermelho-Amarelo, no período de abril a julho de 1996.

Os resultados da análise química de amostras do solo utilizado foram: $\mathrm{pH}$ $\mathrm{H}_{2} \mathrm{O}=6,0: \mathrm{P}$ disponível $=95 \mathrm{mg} / \mathrm{dm}^{3}$; $\mathrm{K}=156 \mathrm{mg} / \mathrm{dm}^{3} ;$ Al trocável $=0,0$ $\mathrm{cmol} / \mathrm{dm}^{3} ; \mathrm{Ca}^{+2}+\mathrm{Mg}=4,75 \mathrm{cmol} / \mathrm{dm}^{3}$ e matéria orgânica $=11,3 \mathrm{~g} / \mathrm{dm}^{3}$. A temperatura média em ${ }^{\circ} \mathrm{C}$, a precipitação 
Tabela 1. Produtividade, peso médio, índice de formato, compacidade de cabeças e tolerância à podridão-negra de híbridos de repolho. Areia, UFPB, 1996.

\begin{tabular}{lccccc}
\hline Híbridos & $\begin{array}{c}\text { Produtividade } \\
\text { (t/ha) }\end{array}$ & $\begin{array}{c}\text { Peso médio de } \\
\text { cabeça(kg) }\end{array}$ & Índice de Compacidade & $\begin{array}{c}\text { Tolerância a } \\
\text { podridão negra } \\
\text { (notas) }\end{array}$ \\
\hline Midore & $30,62 \mathrm{a}$ & $1,314 \mathrm{a}$ & 0,91 & $4,75 \mathrm{a}$ & $1,50 \mathrm{~b}$ \\
Rotan & $31,50 \mathrm{a}$ & $1,355 \mathrm{a}$ & 0,71 & $3,00 \mathrm{~b}$ & $3,50 \mathrm{a}$ \\
Saikô & $25,02 \mathrm{a}$ & $1,075 \mathrm{ab}$ & 1,02 & $4,50 \mathrm{a}$ & $3,50 \mathrm{a}$ \\
Fuyu & $22,46 \mathrm{ab}$ & $0,966 \mathrm{ab}$ & 1,41 & $2,50 \mathrm{~b}$ & $4,00 \mathrm{a}$ \\
Matsukase & $29,12 \mathrm{ab}$ & $1,252 \mathrm{a}$ & 0,91 & $4,75 \mathrm{a}$ & $1,50 \mathrm{~b}$ \\
Roxo & $9,84 \mathrm{~b}$ & $0,522 \mathrm{~b}$ & 1,37 & $5,00 \mathrm{a}$ & $1,50 \mathrm{~b}$ \\
\hline CV(\%) & 27,55 & 25,45 & & 3,89 & 2,75 \\
\hline
\end{tabular}

Médias seguidas da mesma letra não diferem ente si, pelo teste de Tukey, a $5 \%$ de probabillidade.

pluviométrica em mm e a umidade relativa em \% do período foram, respectivamente: abril - 24,9; 14 e 72,37; maio - 23,6; 117,5 e 80,1; junho - 22,11; 107,9 e 81,63 ; julho - 21,47; 173,10 e 82,48 .

Foram avaliados os híbridos Midore, Rotan, Saikô, Fuyu, Matsukaze e Roxo. Inicialmente, realizou-se a produção de mudas em sementeira convencional. Cerca de 30 dias após a semeadura, quando as plântulas apresentavam de 10-15 cm de altura e 4-6 folhas definitivas, foram transplantadas para o local definitivo. No campo, os híbridos foram dispostos em parcelas de $6,40 \mathrm{~m}^{2} \mathrm{com}$ 20 vinte plantas, no espaçamento de 0,80 $\mathrm{m} \times$ 0,40 m, num delineamento experimental de blocos casualizados, sendo testados seis híbridos em quatro repetições. Toda a área da parcela foi considerada útil.

O preparo do solo constou de aração, gradagem, sulcamento à tração mecânica e abertura de covas com auxílio de enxada. Foram feitas adubações de plantio nas covas, utilizando-se $30 \mathrm{t} / \mathrm{ha}$ de esterco bovino curtido, $200 \mathrm{~kg} / \mathrm{ha} \mathrm{de}$ superfosfato simples e $200 \mathrm{~kg} / \mathrm{ha}$ de cloreto de potássio, além de $200 \mathrm{~kg} / \mathrm{ha}$ de sulfato de amônio em cobertura, parcelado aos 30 e 60 dias após o transplantio. Durante a condução da cultura foram realizadas pulverizações à base de Deltametrina 2,5E, a cada quinze dias após o transplantio, visando basicamente o controle de lagarta rosca (Agrotis ypsilon), pulgões (Brevicoryne brassicae) e traçasdas-crucíferas (Plutella xylostella). Utilizou-se a irrigação por aspersão, sempre que necessário, procurando manter o nível de disponibilidade de água acima de $80 \%$ da capacidade de campo. Efetuaram-se também capinas com auxílio de enxadas, procurando-se manter a cultura livre de plantas daninhas.

Na colheita, foram avaliados: o peso médio e a produção total de cabeças; o índice de formato (relação entre o diâmetro longitudinal e transversal da cabeça), onde valores próximos de 1,00 indicaram cabeças mais arredondadas (Castellane \& Braz,1991); compacidade de cabeça, avaliada por notas de 1 a 5 , sendo que o maior valor indicou cabeça mais compacta (Silva Júnior et al., 1987) e a suscetibilidade à podridão negra, avaliada por notas de 1 a 5 , sendo 1 tolerante e 5 muito suscetível (Castellane \& Braz, 1991). Para comparar as médias das características avaliadas empregou-se o teste de Tukey a 5\% de probabilidade, exceto para o índice de formato da cabeça.

\section{RESULTADOS E DISCUSSÃO}

Foram observadas diferenças estatisticamente significativas entre os híbridos para todos os caracteres submetidos às análises estatísticas (Tabela 1).

Os híbridos Midore e Rotan apresentaram peso médio e produtividade de cabeças iguais ao Matsukaze, embora apresentassem valores absolutos superiores. O híbrido Roxo apresentou o pior desempenho dentre os híbridos testados em termos de peso médio e produtividade de cabeças, enquanto o Fuyu apre- sentou resultados intermediários. Com relação ao formato da cabeça, os híbridos Fuyu e Roxo apresentaram valores acima de 1,00, caracterizando-se como materais produtores de cabeças compridas. O híbrido Midore apresentou índice de formato de cabeça igual ao Matsukaze $(0,91)$. Trata-se, portanto, de um híbrido com cabeça mais arredondada, de boa aceitação comercial, enquanto o híbrido Rotan, com menor valor para o índice de formato $(0,71)$, se caracterizou como de cabeças achatadas. Os híbridos Midore, Saikô e Roxo apresentaram compacidade igual à do Matsukaze, com valores 5,00 e 4,75, respectivamente, revelando-se como repolhos de cabeças firmes. Nas condições de alta precipitação em Areia-PB, os híbridos Midore e Roxo destacaramse como tolerantes à podridão negra, a exemplo do Matsukaze.

O híbrido Midore apresentou folhas mais claras e macias ao tato, mostrando-se apropriadas para o consumo na forma de saladas cruas. Considerandose o hibrido Matsukaze como padrão comercial de repolho nos mercados do Centro-Sul e do Nordeste do Brasil, pode-se concluir que existem outros híbridos comparáveis a esse quanto à produtividade, compacidade e nível de tolerância à podridão negra. As principais diferenças estão no aspecto da planta, como coloração, textura, cerosidade e tamanho das folhas externas. Analisando-se os aspectos peso médio, produtividade, tolerância à Xanthomonas, compacidade e formato da cabeça, o híbrido Midore é considerado também 
boa opção de cultivo sob condições chuvosas, na região de Areia-PB.

\section{LITERATURA CITADA}

\section{AGRADECIMENTOS}

Os autores agradecem aos agentes em Agropecuária José Ribeiro Dantas Filho, José Barbosa de Souza, Francisco Soares de Brito, Francisco Silva do Nascimento e Expedito de Souza Lima que viabilizaram a execução dos trabalhos de campo.
CASTELLANE, P. D.; BRAZ, L. T. Avaliação de cultivares de repolho nas condições de primavera, em Jaboticabal - SP. Horticultura Brasileira, Brasília, v. 9, n. 1, p. 13-14, 1991.

FiLGUEIRA, F. A. R. Manual de olericultura: cultura e comercialização de hortaliças. 2 ed. São Paulo: Agronômica Ceres, 1982. 385 p. GIORDANO, L. B. de.; SILVA, N. da.; CORDEIRO, C. M. T. Experimentos comparativos entre híbridos e cultivares de repolho. Horticultura Brasileira, Brasília, v. 3, n. 1, p. 29-31, 1985.
MUNIZ, J. O. L. Avaliação de cultivares e híbridos de repolho. Horticultura Brasileira, Brasília, v. 6, n. 1, p.14-15, 1988 .

SILVA JÚNIOR, A. A.; MIURA, L.; YOKOYAMA, S. Cultivares de repolho de verão em Santa Catarina. Florianópolis, EMPASC, 1987. 19 p (comunicado técnico 11)

SONNENBERG, P. E. Olericultura especial. 3 ed., v. 1. Goiânia: UFG, 1985, 188 p.

VIEIRA, R.F.; RESENDE, M.A.V. de; CASTRO, M.C.S. de. Comportamento de cultivares de grão-de-bico na Zona da Mata e Norte de Min as Gerais. Horticultura Brasileira, Brasília, v. 17, n. 2, p.166-170, julho 1999.

\title{
Comportamento de cultivares de grão-de-bico na Zona da Mata e Norte de Minas Gerais.
}

\author{
Rogério F. Vieira ${ }^{1}$; Maria Aparecida V. de Resende ${ }^{1}$; Maria Cecília S. de Castro ${ }^{1}$ \\ EPAMIG, Vila Gianetti, casa 47, 36571-000 Viçosa - MG.
}

\section{RESUMO}

Este trabalho teve por objetivo avaliar o comportamento de cultivares de grão-de-bico em duas regiões de Minas Gerais. Os ensaios foram conduzidos em Viçosa, Leopoldina (Zona da Mata) e Janaúba (Norte). As temperaturas médias normais anuais do período 19311960 nesses três municípios foram de $19,0^{\circ} \mathrm{C} ; 22,6^{\circ} \mathrm{C}$ e $23,5^{\circ} \mathrm{C}$, respectivamente. Em Viçosa, o ensaio foi instalado em 30 de abril 1991 e foram testadas cinco cultivares; nos outros locais, onde foram testadas doze cultivares, a semeadura foi feita em 16 de maio 1995. Dos genótipos estudados, três pertencem ao grupo "desi" e nove, ao grupo "kabuli". Utilizou-se o espaçamento entre fileiras de 50 ou 60 $\mathrm{cm}$, com 20 sementes por metro. Todos os ensaios foram irrigados por aspersão. Fez-se uso de defensivos químicos para o controle preventivo de doenças e de pragas em Leopoldina e Janaúba. O grãode-bico demorou seis ou nove dias para emergir do solo e, entre 35 e 64 dias depois, dependendo do genótipo e do local, as plantas iniciaram o florescimento. A colheita foi feita entre 105 e 129 dias após a emergência. Em Viçosa e Janaúba, a altura das plantas variou de 45 a $65 \mathrm{~cm}$. Em Viçosa, o grão-de-bico apresentou rendimento máximo de $2.115 \mathrm{~kg} / \mathrm{ha}$; em Janaúba e Leopoldina, 2.838 e 2.950 $\mathrm{kg} / \mathrm{ha}$, respectivamente. O potencial produtivo dos genótipos do grupo "kabuli" foi semelhante ao do grupo "desi". Dentre as cultivares do grupo "kabuli" que apresentam grãos comerciais, sobressaíram as ICCV-3, IAC México e CNPH-2. Em Janaúba, o peso de 100 sementes desses genótipos foi 36, 51 e $42 \mathrm{~g}$, respectivamente.

Palavras-chave: Cicer arietinum, início da floração, rendimento de grãos, ciclo de vida.

\begin{abstract}
Behaviour of chickpea cultivars in "Zona da Mata" and northern Minas Gerais State, Brazil.

This study was undertaken to evaluate the behaviour of chickpea cultivars in two regions of the State of Minas Gerais. The trials were carried out in Viçosa and Leopoldina (Zona da Mata region), and in Janaúba (northern region). The annual average temperatures between 1931-1960 in these municipalities were $19.0^{\circ} \mathrm{C}, 22.6^{\circ} \mathrm{C}$, and $23.5^{\circ} \mathrm{C}$, respectively. In Viçosa, a trial of five cultivars was installed on 30 April 1991. In the other two municipalities, chickpeas were sown on 16 May 1995, testing twelve cultivars. Of the genotypes studied, three belong to the "desi" group and nine to the "kabuli" group. Twenty seeds were planted per meter in rows 50 or $60 \mathrm{~cm}$ apart. All trials were sprinkler irrigated. Pesticides were applied for diseases and pest control in Leopoldina and Janaúba. Emergence from the soil occurred after six or nine days and from 35 to 64 days later plants began flowering, depending on cultivar and locality. Plants were harvested between 105 and 129 days after emergence. In Viçosa and Janaúba, plant height varied from 45 to $65 \mathrm{~cm}$. In Viçosa, maximum yield was 2,115 kg/ha; in Janaúba and Leopoldina, 2,838 and 2,950 $\mathrm{kg} / \mathrm{ha}$, respectively. The potential yield of the two groups was similar. Among the cultivars of the kabuli group, which are commercialized in Brazil, ICCV-3, IAC México, and CNPH-2 excelled. In Janaúba, the one-hundred seed weight of these cultivars was 36,51 , and $42 \mathrm{~g}$, respectively.
\end{abstract}

Keywords: Cicer arietinum, days to flowering, yield, life cycle.

\section{(Aceito para publicação em 08 de março de 1999)}

$\mathrm{E}$ m 1996, foram produzidos no mundo 8,9 milhões de toneladas de grão-de-bico, colhidas em 12 milhões de hectares, com produtividade média de $742 \mathrm{~kg} / \mathrm{ha}$. A Índia é o maior produ- tor mundial com seis milhões de toneladas de grãos. Na América, o México é o maior produtor (152.000 toneladas), com produtividade média de $1.443 \mathrm{~kg}$ / ha (FAO, 1997). Embora seja conside- rada leguminosa de clima frio, grandes áreas são cultivadas em locais com temperaturas relativamente altas, pelo menos durante parte do seu ciclo de vida. Temperaturas entre 15 e $30^{\circ} \mathrm{C}$ proporcio- 